\title{
AARC Clinical Practice Guidelines: Artificial Airway Suctioning
}

\author{
Thomas C Blakeman, J Brady Scott, Mark A Yoder, Emily Capellari, and Shawna L Strickland
}

\author{
Introduction \\ Committee Composition \\ Search Strategy \\ Study Selection \\ Development of Recommendations \\ Assessment and Recommendations \\ Indications for and Complications of Artificial Airway Suctioning \\ Routine Versus As-Needed Only Artificial Airway Suctioning \\ Open Versus Closed System Artificial Airway Suctioning \\ Preprocedure Oxygenation and Hyperoxygenation for Artificial Airway \\ Suctioning \\ Normal Saline Solution Lavage for Artificial Airway Suctioning \\ Clean Versus Sterile Artificial Airway Suctioning Procedure \\ Suction Catheter Size and Applied Vacuum Pressure \\ Duration of the Artificial Airway Suctioning Procedure \\ Shallow Versus Deep Artificial Airway Suctioning Procedure \\ Bronchoscopy Versus Artificial Airway Suctioning \\ Artificial Airway (Tube) Scraping Devices \\ Summary
}

Artificial airway suctioning is a key component of airway management and a core skill for clinicians charged with assuring airway patency. Suctioning of the artificial airway is a common procedure performed worldwide on a daily basis. As such, it is imperative that clinicians are familiar with the most-effective and efficient methods to perform the procedure. We conducted a systematic review to assist in the development of evidence-based recommendations that pertain to the care of patients with artificial airways. From our systematic review, we developed guidelines and recommendations that addressed questions related to the indications, complications, timing, duration, and methods of artificial airway suctioning. By using a modified version of the RAND/UCLA Appropriateness Method, the following recommendations for suctioning were developed for neonatal, pediatric, and adult patients with an artificial airway: (1) breath sounds, visual secretions in the artificial airway, and a sawtooth pattern on the ventilator waveform are indicators for suctioning pediatric and adult patients, and an acute increase in airway resistance may be an indicator for suctioning in neonates; (2) as-needed only, rather than scheduled, suctioning is sufficient for neonatal and pediatric patients; (3) both closed and open suction systems may be used to safely and effectively remove secretions from the artificial airway of adult patients; (4) preoxygenation should be performed before suctioning in pediatric and adult patients; (5) the use of normal saline solution should generally be avoided during suctioning; (6) during open suctioning, sterile technique should be used; (7) suction catheters should occlude $<70 \%$ of the endotracheal tube lumen in neonates and $<50 \%$ in pediatric and adult patients, and Suction pressure should be kept below $-120 \mathrm{~mm} \mathbf{H g}$ in neonatal and pediatric patients and $-200 \mathrm{~mm}$ $\mathrm{Hg}$ in adult patients; (8) suction should be applied for a maximum of $15 \mathrm{~s}$ per suctioning procedure; 
(9) deep suctioning should only be used when shallow suctioning is ineffective; (10) routine bronchoscopy for secretion removal is not recommended; and (11) devices used to clear endotracheal tubes may be used when airway resistance is increased due to secretion accumulation. [Respir Care 2022;67(2):258-271. (c) 2022 Daedalus Enterprises]

\section{Introduction}

Secretion management is vital to effective gas exchange, especially in the patient with an artificial airway. It is incumbent on the health-care team to ensure safe and effective secretion removal in patients with artificial airways. Artificial airway suctioning is a common procedure performed daily along the care continuum worldwide. This procedure includes patient preparation, application of suction via the introduced catheter, and post-procedure care. ${ }^{1}$ Although generally considered safe, the application of artificial airway suctioning through either an endotracheal tube (ETT) or tracheostomy tube is not without potential complications. Transient adverse events such as oxygen desaturation, bleeding, hemodynamic changes, and alterations in heart rate have been reported. ${ }^{2-4}$ Poor airway suctioning practices may lead to longer-term consequences, such as damage to the airway mucosa ${ }^{5}$ and hospital-acquired infections. ${ }^{3}$

A previous clinical practice guideline (CPG) published by the American Association for Respiratory Care (AARC) in 2010 focused on this procedure. ${ }^{1}$ The 2010 AARC clinical practice guideline generated 10 recommendations for safe endotracheal suctioning of patients on mechanical ventilation and with artificial airways that were informed by a detailed literature review. Methods of suctioning the artificial airway have varied over time, and the scientific evidence that drives current clinical practices has evolved. As such, we conducted

Mr Blakeman is affiliated with the Section of General Surgery, University of Cincinnati, Cincinnati, Ohio. Dr Scott is affiliated with the Division of Respiratory Care, Department of Cardiopulmonary Sciences, Rush University, Chicago, Illinois. Dr Yoder is affiliated with the Division of Pulmonary, Critical Care, and Sleep Medicine, Department of Medicine, Rush University Medical Center, Chicago, Illinois. Ms Capellari is affiliated with the Taubman Health Sciences Library, University of Michigan, Ann Arbor, Michigan. Dr Strickland is affiliated with the American Epilepsy Society, Chicago, Illinois, and College of Health Sciences, Rush University, Chicago, Illinois. At the time of this work Dr Strickland was affiliated with the American Association for Respiratory Care.

Dr Scott discloses a relationship with Teleflex. The other authors have disclosed no conflicts of interest.

Supplementary material related to this paper is available at http://www. rcjournal.com

Correspondence: Shawna L Strickland PhD RRT RRT-NPS RRT-ACCS AE-C FAARC, Department of Health Sciences, College of Health Sciences, Rush University, 600 South Paulina Suite 1001 AAC, Chicago, IL 60612. E-mail: Shawna_L_Strickland@rush.edu.

DOI: $10.4187 /$ respcare.09548 a systematic review of the literature to update, when appropriate, recommendations for effective artificial airway secretion clearance. The CPG developed from this systematic review focused on the following questions relevant to artificial airway suctioning of neonatal, pediatric, and adult patients:

1. What are the indications for and complications of artificial airway suctioning in the neonatal, pediatric, and adult population?

2. Should artificial airway suctioning be performed on a schedule or only on an as-needed basis?

3. Should artificial airway suctioning be performed by using open or closed systems?

4. Should patients be preoxygenated and/or hyperoxygenated before suctioning?

5. Should normal saline solution lavage be used during suctioning of the artificial airway?

6. Should open suctioning of an artificial airway be performed as a clean procedure or as a sterile procedure?

7. What size of suction catheter and what vacuum pressure should clinicians use to suction artificial airways?

8. What limit should be imposed on the duration of the suctioning event?

9. Is a shallow suctioning technique preferred over a deep suctioning technique?

10. When should bronchoscopy be used in lieu of open or closed suctioning techniques?

11. When should tube scraping devices be used in addition to suction catheters?

\section{Committee Composition}

A committee was selected by the AARC leadership based on their known experience related to the topic, their interest in participating in the project, and their commitment to the process details. The committee first met face to face, where they were introduced to the process of developing CPG. At that time, the committee selected a chair and wrote a first draft of PICO (patient, intervention, comparison, outcome) questions. Subsequent meetings occurred as needed by conference call. Frequent e-mail communications occurred among the committee members and the AARC staff. The committee members received no remuneration for their participation in the process, although their expenses for the face-to-face meeting were covered by the AARC. 


\section{AarC Clinical Practice Guidelines: Artificial Airway Suctioning}

\section{Search Strategy}

A literature search was conducted by using the PubMed, CINAHL via EBSCOhost, and the Scopus.com databases on studies of artificial airway suctioning in neonatal, pediatric, and adult subjects. The search strategies used a combination of controlled vocabulary (ie, Medical Subject Headings and CINAHL headings) and keyword variations that related to artificial airway suctioning indications, complications, techniques, and outcomes. The searches were limited to English language studies on human populations. The searches were also designed to filter out citations indexed as commentaries, editorials, interviews, news, or reviews. No date restrictions were applied to the searches. The complete search strategy executed in each database is available in an online supplement (see the supplementary materials at http://www. rcjournal.com). Duplicate citations were identified and removed by using EndNote X7 citation management software (Clarivate Analytics, Philadelphia, Pennsylvania).

\section{Study Selection}

At least two reviewers (TCB, JBS, SLS) independently assessed study eligibility in the Covidence systematic review software (Melbourne, Australia). Inclusion criteria used to assess eligibility were the following: (1) artificial airway (including laryngectomy and tracheal T tubes); (2) tube scraping devices; (3) neonatal, pediatric, and adult populations; and (4) English language. The exclusion criteria used were the following: (1) natural airway suctioning, (2) case study, (3) bench study, (4) not empirical research (eg, theory or opinion articles), (5) non-English language studies, and (6) animal studies.

\section{Development of Recommendations}

It is recognized that a process is necessary to combine the best available evidence with the collective experience of the committee members. To achieve this, a modification of the RAND/UCLA appropriateness method was used. ${ }^{6}$ The literature was collapsed into evidence tables according to the PICO question (Supplementary Table 1 [see the supplementary materials at http://rc.rcjournal.com]). Individual panel members were assigned the task of writing a systematic review of the topic, drafting one or more recommendations, and suggesting the level of evidence supporting the recommendation as follows:

A. Convincing scientific evidence based on randomized controlled trials of sufficient rigor.

B. Weaker scientific evidence based on lower levels of evidence, such as cohort studies, retrospective studies, case-control studies, and cross-sectional studies.

C. Based on the collective experience of the committee.
Committee members reviewed the first draft of evidence tables, systematic reviews, recommendations, and evidence levels. Each committee member rated each recommendation by using a Likert scale of 1 to 9 , with 1 meaning that expected harms greatly outweigh the expected benefits and 9 meaning that expected benefits greatly outweigh the expected harms. The ratings were returned to the committee chair. The first ratings were done with no interaction among the committee members. A conference call was convened, during which time the individual committee ratings were discussed. Particular attention was given to any outlier scores and the justification. Recommendations and evidence levels were revised with input from the committee members. After discussing each PICO question, committee members again rated each recommendation. The final median and range of committee members' scores are reported. Strong agreement required that all the committee members rank the recommendation $\geq 7$, weak agreement meant that one or more committee members ranked the recommendation $<7$, but the median vote was at least 7 . For recommendations with weak agreement, the percentage of committee members who rated $\geq 7$ was calculated and reported after each weak recommendation. The process flow that the panel used to rate the appropriateness and quality of the literature selected through the search process is illustrated in Figure 1. Drafts of the report were distributed among the committee members in several iterations. When all the committee members were satisfied, the document was submitted for publication. The report was subjected to peer review before final publication.

\section{Assessment and Recommendations}

The search strategies retrieved a total of 1,667 articles. After the removal of duplicates, 1,134 articles remained for screening, of which 831 were excluded at the title and abstract level. Of the remaining 303 articles, 219 were excluded after full-text review against the inclusion and exclusion criteria (Fig. 2). Unless otherwise stated, recommendations apply to neonatal, pediatric, and adult patient populations.

\section{Indications for and Complications of Artificial Airway Suctioning}

Retained tracheobronchial secretions are common in patients with an artificial airway. It is important for the caregiver to recognize when suctioning is warranted as well as the potential complications and hazards. A review of the literature yielded 27 relevant studies., ${ }^{2,47-31}$

Indications. Five studies ${ }^{7-11}$ focused on the indications for ETT suctioning. One study in the neonatal population found a statistically significant increase in airway resistance $\left(\mathrm{R}_{\mathrm{aw}}\right)$ $(P<.01)$ and, therefore, recommended monitoring $\mathrm{R}_{\mathrm{aw}}$ to 


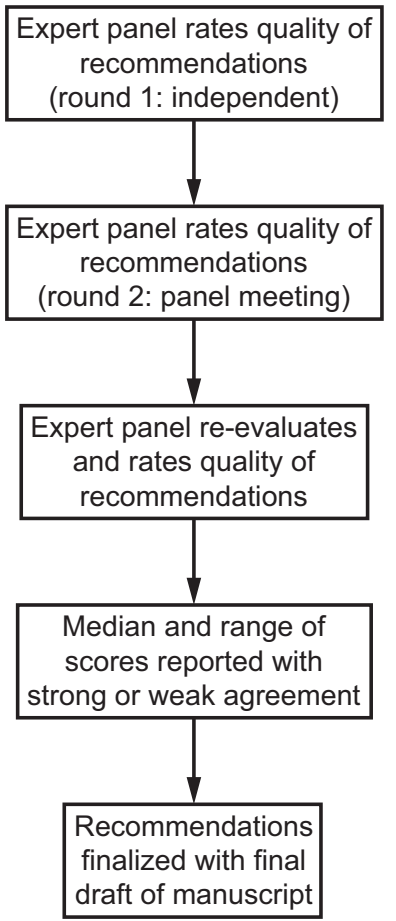

Fig. 1. Literature appraisal process.

determine the need for suctioning. ${ }^{7}$ One study in pediatric patients showed that ETT suctioning in subjects with respiratory crackles noted in the operating room and postanesthesia care unit resulted in improved $\mathrm{S}_{\mathrm{pO}_{2}}$, with no change in airway pressure, end-tidal $\mathrm{CO}_{2}$ and blood pressure compared with subjects who did not receive suctioning. ${ }^{8}$

In the adult population, Guglielminotti et $\mathrm{al}^{9}$ found that a sawtooth pattern on the ventilator flow waveform, visible secretions in the ETT, and respiratory sounds heard when auscultating over the trachea were good indicators of the need for suctioning $(P<.001)$. Results from Sole et $\mathrm{al}^{10}$ corroborated these indicators, with the exception of visible secretions $(P=.5)$. The volume of secretions $(\geq 0.5 \mathrm{~mL})$ retrieved during suctioning was associated with several of the previous listed indicators but was not statistically significant $(P=.17)$, although there was significant improvement in all indicators after suctioning $(P<.001)$. Lucchini et $\mathrm{al}^{11}$ found that the use of an acoustic secretion detector served as a better indication of secretions in the airway and the need for artificial airway suctioning than the indicators in the previous studies and resulted in significantly fewer suctioning adverse events $(P<.001)$.

Complications. Twenty-two studies ${ }^{2,4,12-31}$ focused on the complications associated with artificial airway suctioning. In the adult patient population, Beuret et $\mathrm{al}^{12}$ showed that the ability of the ETT cuff to seal the airway was not significantly affected by suctioning $(P=.06)$. In neonatal subjects, Durand et $\mathrm{al}^{13}$ showed that ETT suctioning significantly

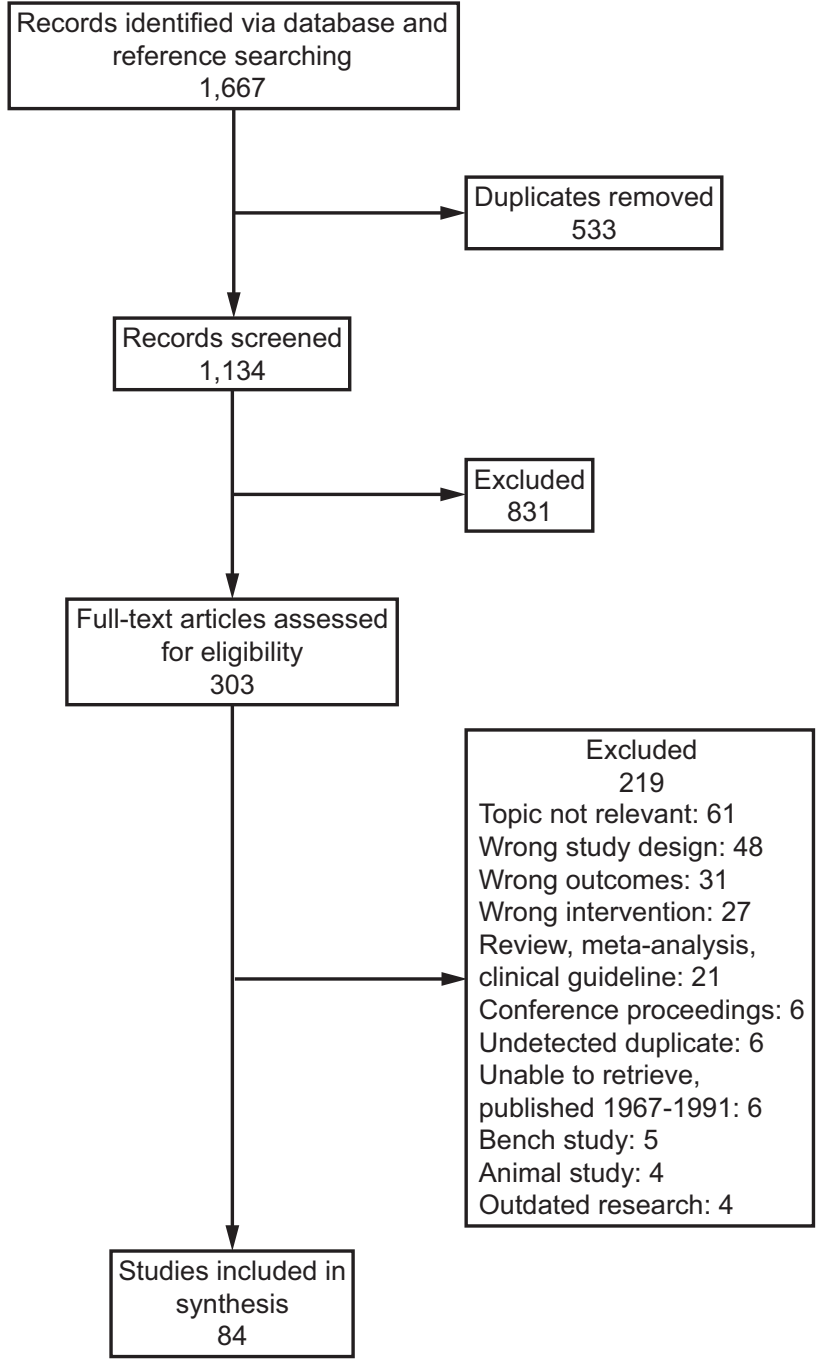

Fig. 2. Flow chart.

affected heart rate, mean arterial pressure, intracranial pressure (ICP), and cerebral perfusion pressure $(P<.05)$. In a study by Fanconi et al, ${ }^{14}$ ICP was significantly lower $(P<$ $.001)$ when neuromuscular blockers were given before suctioning. All other physiologic responses were not significantly affected by suctioning. Simbruner et $\mathrm{a}^{15}$ reported that transcutaneous $\mathrm{P}_{\mathrm{O}_{2}}$ and heart rate were significantly decreased, and the mean arterial pressure significantly increased during suctioning $(P<.05)$ but not at 1,2 , and 5 $\mathrm{min}$ after. Kaiser et $\mathrm{al}^{16}$ documented prolonged increases in cerebral blood flow velocity after suctioning, which could be of concern because this parameter has been associated with brain injury in very low birthweight neonates. Tingay et $\mathrm{al}^{17}$ found that, in neonates receiving high-frequency oscillatory ventilation, artificial airway suctioning was associated with significant decreases in lung volume $(P<.001)$. However, they did note that lung volumes recovered within $60 \mathrm{~s}$ to near baseline levels $(P>.05){ }^{17}$ 
In the pediatric population, Morrow et $\mathrm{al}^{18}$ found that changes in lung compliance, expired tidal volume, breathing frequency, and minute ventilation were significantly different after than before artificial airway suctioning $(P<.05)$. Scoble et $\mathrm{al}^{19}$ found that reusing a suction catheter for $24 \mathrm{~h}$ did not affect the incidence of pneumonia compared with when using a new catheter with each artificial airway suctioning event $(P>.05)$. Boothroyd et $\mathrm{al}^{20}$ found that using graduated suction catheters and controlled vacuum pressures resulted in a significantly lower incidence of right upper lobe collapse compared with standard practice $(P<.05)$. Fisher et $\mathrm{al}^{21}$ found that ICP increases in children with brain injury were due to tracheal stimulation from artificial airway suctioning rather than increased $\mathrm{P}_{\mathrm{CO}_{2}}$ due to apnea when detaching the subject from the ventilator before suctioning $(P<.05)$.

In an adult population, Jongerden et $\mathrm{al}^{22}$ found significant increases in heart rate and mean arterial pressure $(P<$ .01) but not $\mathrm{S}_{\mathrm{pO}_{2}}$ after artificial airway suctioning by using both open and closed techniques. Maggiore et $\mathrm{al}^{2}$ found that adverse events due to artificial airway suctioning were significantly reduced after implementing practice guidelines $(P<.05)$ but that there was no difference in ICU length of stay (LOS) or ventilator days. Three studies showed significant differences from baseline in ICP, cerebral perfusion pressure, and mean arterial pressure after artificial airway suctioning $(P<.05) \cdot{ }^{23-25}$ Clark et $\mathrm{al}^{26}$ found that oxygen saturation measured on a mixed venous blood sample, $\mathrm{S}_{\mathrm{vO}}$ was significantly lower at 1 and 2 min after artificial airway suctioning with both open and closed suctioning techniques with $100 \%$ preoxygenation $(P<.001)$ but returned to baseline values within $3 \mathrm{~min}$. Bourgault et $\mathrm{al}^{27}$ found that artificial airway suctioning with both open and closed techniques did not affect heart rate variability and systolic blood pressure when preoxygenated with $100 \%$ oxygen for at least $1 \mathrm{~min}$.

A study conducted by Guglielminotti et $\mathrm{al}^{28}$ showed that artificial airway suctioning caused a significant increase in $\mathrm{R}_{\mathrm{aw}}(P<.01)$ and intrinsic PEEP $(P<.05)$. A study by Van de Leur et $\mathrm{al}^{29}$ found that artificial airway suctioning when using saline solution lavage compared with minimally invasive suction with no lavage produced significant increases in oxygen desaturation $(P=.001)$, cardiac arrhythmias $(P=.002)$, systolic blood pressure $(P=.003)$, blood in respiratory secretions $(P=.001)$, and subject recollection of the suctioning event $(P=.001)$. In a separate study, Van de Leur et $\mathrm{a}^{30}$ found these same adverse effects, excluding subject recollection, but found no significant difference $(P>.05)$ in duration of intubation, mortality, ICU LOS, or infection when using invasive compared with minimally invasive artificial airway suctioning techniques. Seymour et $\mathrm{al}^{4}$ reported that minute ventilation, mean arterial pressure, heart rate, and rapid shallow breathing index were significantly increased after ETT suctioning $(P<$ $.05)$. Recovery time ranged from 1 to $7 \mathrm{~min}$. Walsh et al ${ }^{31}$ found the following changes after open ETT suctioning preceded by hyperinflation with $100 \%$ oxygen was performed: $\mathrm{S}_{\mathrm{vO}_{2}}$ was significantly decreased $(P<.05)$, oxygen consumption was significantly increased $(P<.05)$, but $\mathrm{S}_{\mathrm{aO}_{2}}$ and cardiac output were not significantly different $(P>.05)$.

Based on the available evidence, breath sounds, visible secretions in the artificial airway, and sawtooth pattern on the ventilator flow waveform are the best indicators of the need for artificial airway suctioning in the adult and pediatric population (evidence level $\mathrm{B}$, all the committee members rated the appropriateness score at 8). An acute increase in $R_{a w}$ may be an indicator for the need for artificial airway suctioning in neonates (evidence level B, median appropriateness score 7, range 7-8). Physiologic responses to artificial airway suctioning such as increased heart rate, mean arterial pressure, ICP, cardiac arrythmias, and oxygen desaturation are among the potential complications in all patient populations. Significant decreases in lung volume were noted post-suctioning as well as decreases in cerebral blood flow velocity in neonates. Mitigation strategies such as adequate sedation, preoxygenation, and suctioning only when indicated may reduce the incidence and severity of these complications (evidence level B; median appropriateness score 7.6, range 7-9).

\section{Routine Versus As-Needed Only Artificial Airway Suctioning}

The frequency at which to perform artificial airway suctioning remains controversial. A review of the literature yielded 2 studie $^{32,33}$ related to frequency of suctioning: one study each in neonatal and pediatric patient populations. In a randomized, controlled trial of 180 very low birthweight neonates randomized to artificial airway suctioning every $4 \mathrm{~h}$ or every $8 \mathrm{~h}$, plus as needed, Cordero et al ${ }^{32}$ found no difference in mechanical ventilation days, hospital LOS, bloodstream infections, ventilator-associated pneumonia (VAP), or adverse events between the groups. In a randomized controlled trial of 90 pediatric subjects randomized to artificial airway suctioning either every $2 \mathrm{~h}$ or as-needed only, Lema-Zuluaga et $\mathrm{al}^{33}$ showed no difference in VAP, mechanical ventilation days, ICU LOS, or mortality between the 2 groups. No studies were found that addressed suctioning frequency in the adult patient population. Based on the evidence presented in these studies, as-needed suctioning is just as effective as routine suctioning and does not increase morbidity or mortality in neonatal and pediatric populations. The current evidence supports the previous recommendation advanced in the 2010 AARC CPG $^{1}$ to perform airway suctioning of the artificial airway only as needed (evidence level B, all the committee members rated the appropriateness score at 8).

\section{Open Versus Closed System Artificial Airway Suctioning}

Since the development of closed suction system devices in the early 1990s, researchers have sought to compare the 
resultant clinical outcomes with those of the traditional open suction system. This systematic review included 28 studies $^{22,27,34-59}$ focused on relevant clinical outcomes that compared closed suction system with the open suction system. The majority of the studies ${ }^{22,27,36,39-46,48,49,51,52}$ included physiologic outcomes and the development of hospitalacquired infections. Two studies $s^{34,35}$ that compared the closed suction system with the open suction system focused on secretion management. Witmer et $\mathrm{al}^{34}$ studied adult subjects who were intubated. They compared the quantity of secretions removed during artificial airway suctioning and found that secretions removed via closed suction system (median $1.7 \mathrm{~g}$ ) and the quantity removed via the open suction system (median $1.9 \mathrm{~g})(P=.88)$ were not statistically different. ${ }^{34}$ Lasocki et al ${ }^{35}$ studied the effects of the closed suction system and the open suction system on secretion removal in 9 adult subjects who were intubated. They discovered that the mean aspirate mass was larger with the open suction system (mean $3.2 \mathrm{~g}$ ) than with the closed suction system (mean $0.6 \mathrm{~g})(P=.03){ }^{35}$ The small sample size of this latter study raises concern about the generalizability of this finding.

Several studies ${ }^{22,27,36,39-46,48,49,51,52}$ evaluated changes in physiologic parameters in response to the closed suction system and the open suction system. Studies that enrolled adult subjects focused on parameters such as heart rate, breathing frequency, $\mathrm{S}_{\mathrm{pO}_{2}}$, pain, agitation, cardiac dysrhythmias, and ICP. ${ }^{22,27,36-42}$ Most of these studies found no significant difference in the outcomes between the closed suction system or the open suction system, although some studies $^{35,43,44}$ did see some minor differences. Johnson et $\mathrm{al}^{43}$ noted that the closed suction system had fewer physiologic disturbances (heart rate, blood pressure, $\mathrm{S}_{\mathrm{pO}_{2}}$, dysrhythmias) than the open suction system. Lasocki et $\mathrm{al}^{35}$ noted that oxygenation and ventilation were better maintained with the closed suction system. Uğraş and Aksoy ${ }^{44}$ found that the closed suction system had less impact on ICP during and after the suctioning event and less impact on the mean arterial pressure during the suctioning event than with the open suction system.

Several pediatric and neonatal studies focused on physiologic parameters as well. ${ }^{45-52}$ Changes after suctioning with the closed suction system or the open suction system were similar to those found in the adult studies and likely transient. Evans et $\mathrm{al}^{48}$ found a lower incidence of physiologic disturbances (heart rate, $\mathrm{S}_{\mathrm{pO}_{2}}$, mean arterial pressure) with the closed suction system than with the open suction system. Kalyn et $\mathrm{al}^{49}$ noted that there was less physiologic instability with the closed suction system than with the open suction system.

Most of the outcome-oriented studies that compared open with closed suctioning focused on rates of bacterial colonization and VAP/ventilator associated events (VAE). The majority of these studies were in adult subjects, although a few studies included neonatal and pediatric subjects. ${ }^{37,42,50,53-59}$ Cordero et $\mathrm{al}^{53}$ compared infection rates with the use of the closed suction system and the open suction system in neonates. They found that the difference in rates of airway colonization and nosocomial pneumonia were not statistically different between the 2 methods. ${ }^{53}$ Morrow et a ${ }^{50}$ performed an 8-month study that compared various outcomes of the closed suction system versus the open suction system in pediatric subjects who were intubated and who received mechanical ventilation for $>24 \mathrm{~h}$. The rate of VAP was not statistically different between the 2 methods $(P=.6) .^{50}$

Almost all of the studies that focused on adults who were intubated ${ }^{37,42,53-59}$ found no statistically significant differences in $\mathrm{VAP} /$ ventilator associated event rates, colonization rates, transmission rates, or rates of hospital-acquired infection. One study ${ }^{56}$ did find a difference in colonization rate between the closed suction system $(67 \%)$ and the open suction system $(39 \%)(P<.02)$ but that did not translate into an increased number of infections. One study looked at the rates of mucus plugging between the 2 suction methods. Akerman et $\mathrm{al}^{37}$ found more occurrences of ETT occlusion with the closed suction system but not at a statistically significant level.

Of the 28 included studies for this research question, 5 studied the impact of the closed suction system and the open suction system on outcomes related to mortality, hospital and ICU LOS, and time spent on mechanical ventilation. ${ }^{37,42,50,55,58}$ Four of the studies included adult subjects who were intubated..$^{37,42,55,58}$ None of these studies showed a statistical difference between the closed suction system and the open suction system on mortality, hospital LOS, ICU LOS, or duration of mechanical ventilation. Morrow et $\mathrm{al}^{50}$ as previously discussed, found the same results: no statistical difference in mortality, hospital LOS, ICU LOS, or duration of mechanical ventilation.

Based on the quantity and quality of the included evidence, either the closed suction system or the open suction system can be used safely and effectively to remove secretions from the adult patient with an artificial airway. Although the differences in outcomes between the closed suction system and the open suction system in pediatric and neonatal patients are minimal, using a closed suction system with this population is logical. The clinician is urged to use appropriate infection control measures and safety precautions to avoid unnecessary adverse reactions, such as physiologic changes and damage to the airway mucosa (evidence level B, median appropriateness score 8.3, range 7-9).

\section{Preprocedure Oxygenation and Hyperoxygenation for Artificial Airway Suctioning}

Artificial airway suctioning may cause a clinically important decrease in oxygenation in some patients. A review of the available literature on hyperoxygenation before suctioning yielded 6 studies ${ }^{39,60-64}$ with 3 of these being 
published in the 1990s. ${ }^{60-62}$ In a randomized crossover trial with 25 pediatric subjects on mechanical ventilation, Kerem et $\mathrm{al}^{60}$ found that preoxygenation with $100 \%$ oxygen prevented hypoxemia during suctioning, whereas hyperinflation by using baseline $\mathrm{F}_{\mathrm{IO}_{2}}$ did not. Lookinland and Appel $^{61}$ obtained similar results in an adult population. Preusser et al $^{62}$ conducted a randomized crossover trial with 10 adult subjects on mechanical ventilation by using 1 of 2 lung volumes at $\mathrm{F}_{\mathrm{IO}_{2}} 1.0$ with the ventilator or manual resuscitation bag. There was no statistically significant difference in $\mathrm{P}_{\mathrm{a}} \mathrm{O}_{2}$, mean arterial pressure, or cardiac output between any of the 4 combinations, but peak airway pressure was significantly greater $(P<.001)$ with the manual resuscitation bag. de Freitas Vianna et $\mathrm{al}^{63}$ conducted a prospective crossover study of 68 adult subjects who were preoxygenated with $\mathrm{F}_{\mathrm{IO}_{2}} 1.0$ and $\mathrm{F}_{\mathrm{IO}_{2}} 0.2$ above baseline. No difference was found in $\mathrm{S}_{\mathrm{pO}_{2}}$, heart rate, mean arterial pressure, or breathing frequency before or after suctioning. A prospective crossover trial of 30 adult subjects conducted by Demir and Dramali ${ }^{64}$ found significant decreases in $\mathrm{S}_{\mathrm{pO}_{2}}$ and $\mathrm{P}_{\mathrm{aO}_{2}}$ but not heart rate or mean arterial pressure, after artificial airway suctioning without preoxygenation compared with preoxygenation with $100 \%$ oxygen.

Although the evidence supports preoxygenation, it seems that $100 \%$ oxygen is not required for all patients. The 2010 AARC $\mathrm{CPG}^{1}$ recommended using $100 \%$ oxygen to preoxygenate adult and pediatric patients before suctioning either by manually adjusting the oxygen or by using the temporary preoxygenation program on the ventilator. Manual ventilation to provide preoxygenation was not recommended. There is currently available evidence that these recommendations are appropriate, although preoxygenation with an $\mathrm{F}_{\mathrm{IO}_{2}} 0.2$ above baseline, rather than an increase to $\mathrm{F}_{\mathrm{IO}_{2}}$ 1.0, may be sufficient in adult and pediatric patients. No evidence was available with regard to preoxygenation in the neonatal population (evidence level $\mathrm{B}$, all the committee members rated the appropriateness score at 9).

\section{Normal Saline Solution Lavage for Artificial Airway Suctioning}

There has been considerable research on the effects of using normal saline solution during artificial airway suctioning. The theoretical advantages of using normal saline solution are loosening secretions and increasing the volume of secretions removed during suctioning. ${ }^{1}$ A review of the literature yielded 8 studies that focused on the impact of normal saline solution use during artificial airway suctioning on oxygenation. ${ }^{65-72}$ Results of 7 of these studies suggest that normal saline solution may negatively affect oxygenation. These studies were small, but indicated that measures such as $\mathrm{P}_{\mathrm{aO}_{2}}, \mathrm{~S}_{\mathrm{PO}_{2}}$, and $\mathrm{S}_{\mathrm{vO}_{2}}$ may be unfavorably impacted by artificial airway suctioning, ${ }^{65,67,69-72}$ even when other physiologic measures such as heart rate and blood pressure are not impacted. ${ }^{66}$ Normal saline solution use during artificial airway suctioning has also been shown to increase dyspnea in patients $\geq 60$ years of age. ${ }^{73}$

McKinley et $\mathrm{al}^{74}$ performed a randomized trial to evaluate the hours of intubation and invasive mechanical ventilation in pediatric subjects. They found that using no saline solution was as effective as using quarter-normal or normal saline solution. $^{74}$ In a prospective observational study, Owen et $\mathrm{al}^{71}$ noted more adverse events in pediatric subjects who received normal saline solution during suctioning events. A randomized clinical trial by Caruso et $\mathrm{al}^{75}$ noted a decrease in microbiologically proven VAP with the use of normal saline solution during artificial airway suctioning. Although this finding is interesting, it has not been corroborated in another study to this point.

The 2010 AARC CPG $^{1}$ recommended against the routine use of normal saline solution. Since that guideline, no new evidence convincingly impacts that recommendation. Normal saline solution instillation, if ever performed, should be done so sparingly and with consideration of the potential for adverse events, such as a decrease in oxygen saturation, excessive coughing, bronchospasm, tachycardia, dyspnea, an increase in ICP, and the dislodgement of bacterial biofilm on the inside of the artificial airway. Based on the currently available evidence, it seems that the routine use of normal saline solution is unnecessary during artificial airway suctioning (evidence level B, median appropriateness score 9, range 8-9).

\section{Clean Versus Sterile Artificial Airway Suctioning Procedure}

As previously discussed, both the open suction system and closed suction system procedures can be used safely and effectively to remove secretions from an artificial airway. When performing an open artificial airway suctioning procedure, the clinician must maintain an environment that protects both the patient and the clinician from pathogens. However, questions arise with regard to whether the procedure should be a clean procedure, one that is free from visually obvious contamination, or a sterile procedure, one that is free from bacteria or microorganisms. Some clinicians argue that the sterility of the clinician is irrelevant because the open suction catheter will pass through a non-sterile field, and subsequent passes of the catheter will no longer be sterile. ${ }^{76}$

This systematic review of the literature found no studies focused on patient outcomes when comparing the clean versus sterile open suctioning procedure. Past $\mathrm{CPG}^{1}$ have evaluated this research question. The Centers for Disease Control and Prevention 2003 Guidelines for Preventing Health-Care Associated Pneumonia ${ }^{77}$ recognized that tracheal suctioning does increase the 
opportunity for cross-contamination and that the risk of cross-contamination can be reduced by using an aseptic (sterile) technique. However, the committee was unable to make a recommendation for using a sterile rather than a clean technique when performing endotracheal suctioning. The 2010 AARC $\mathrm{CPG}^{1}$ was also unable to make a recommendation, although it did state that the clinician is encouraged to use the sterile technique throughout the suctioning procedure.

There is a gap in the literature with regard to clinically relevant outcome differences between clean and sterile technique for artificial airway suctioning. However, it is potentially unethical to recommend that further research be conducted to address this gap because the potential for harm with a less-than-sterile environment is a distinct possibility. Therefore, based on committee experience, it is recommended that the clinician use a sterile procedure, when possible, for open suctioning events to protect the patient from potential cross-contamination (evidence level $\mathrm{C}$, all the committee members rated the appropriateness score at 7). At a minimum, in addition to performing hand hygiene on entering and leaving a patient's room or area, the clinician should perform hand hygiene immediately before performing open suctioning to minimize the risk of introducing any new pathogens into the artificial airway.

\section{Suction Catheter Size and Applied Vacuum Pressure}

Research that evaluated the safety and effectiveness of various catheter sizes and applied vacuum pressures is scarce. In a within-subjects repeated-measures study, Javadi et $\mathrm{al}^{78}$ evaluated the impact of different sizes of suction catheters on various outcomes such as heart rate, blood pressure, $\mathrm{S}_{\mathrm{pO}_{2}}$, secretion amount, and pain in adult subjects. In their study, all the subjects were intubated with a size 7.5 inner diameter ETT and were suctioned with both 12 French and 14 French suction catheters randomly assigned according to study protocol. All the subjects were suctioned with both catheter sizes. They reported a significant increase in heart rate, systolic blood pressure, pain, and secretion amount with the use of the larger catheter.

Yousefi et $\mathrm{al}^{79}$ conducted a randomized trial that evaluated the impact of 2 levels of applied vacuum pressure $(-100$ and $-200 \mathrm{~mm} \mathrm{Hg})$ on physiologic indices in adult subjects. They noted that $\mathrm{S}_{\mathrm{pO}_{2}}$ and heart rate was significantly different before, during, and $5 \mathrm{~min}$ and 20 min after suctioning, but there was no difference between the 2 groups. In a prospective study by Singh et $\mathrm{al},{ }^{80}$ the effect of suction catheter outer diameter size in reference to the ETT inner diameter size (small, 0.4; medium, 0.7; and large, 0.9) and vacuum pressures (80, 100 , and $120 \mathrm{~mm} \mathrm{Hg}$ ) on various physiologic indices were assessed in pediatric subjects. They found that all suction catheter sizes at varying pressures similarly influenced the physiologic indices.

Based on the available evidence, it seems that various suction catheter sizes and vacuum pressures can cause physiologic alterations. That said, the optimal suction catheter outer diameter size to artificial airway inner diameter size ratio is not known at this time. The optimal applied vacuum pressure that is both safe and effective at clearing secretions is also not known. The 2010 AARC $\mathrm{CPG}^{1}$ recommended that suction catheters should occlude $<50 \%$ of the ETT lumen in pediatric and adult patients, and $<70 \%$ in neonates. No new evidence convincingly refutes this recommendation (evidence level $\mathrm{C}$, all the committee members rated the appropriateness score at 7).

There was no formal recommendation on applied vacuum pressure in the previous guideline due to the overall lack of data to support a recommendation. ${ }^{1}$ There is minimal evidence that suction pressures should be kept below $-200 \mathrm{~mm} \mathrm{Hg}$ in adults and between -80 and $-100 \mathrm{~mm} \mathrm{Hg}$ in neonates (evidence level C, all the committee members rated the appropriateness score at 7). Efforts to set the suction pressure as low as possible to effectively clear secretions should be made (evidence level $\mathrm{C}$, all committee members rated the appropriateness score at 9).

\section{Duration of the Artificial Airway Suctioning Procedure}

Limiting the duration of each session is an intuitive strategy to mitigate the potential complications and/or hazards of artificial airway suctioning. This limitation could apply to either the amount of time the suction catheter is introduced into the artificial airway or the amount of time that suction is applied. Unfortunately, this review of the literature did not find studies that compared patient outcomes with varying lengths of time the catheter is introduced into the airway and/or suction is applied. Most sources, predominantly previous $\mathrm{CPG},{ }^{1}$ editorials, ${ }^{76,81}$ and textbook chapters ${ }^{82}$ recommend limiting the duration of the procedure to $\leq 15 \mathrm{~s}$. The committee's experience is commensurate with these sources, and the committee recommends keeping each suctioning event as brief as possible and no longer than $15 \mathrm{~s}$ (evidence level $\mathrm{C}$, all the committee members rated the appropriateness score at 7 ).

\section{Shallow Versus Deep Artificial Airway Suctioning Procedure}

Research that evaluated the safety and effectiveness of shallow versus deep artificial airway suctioning techniques is limited. Two methodologically similar articles $^{83,84}$ were published that compared the effects of 
shallow and deep ETT suctioning on physiologic indices. Abbasinia et $\mathrm{al}^{83}$ evaluated the 2 techniques on changes to breathing frequency and $\mathrm{S}_{\mathrm{PO}_{2}}$. In this randomized trial, both the shallow suctioning and deep suctioning groups were preoxygenated and suctioned at the same vacuum pressure $(-120 \mathrm{~mm} \mathrm{Hg})$ a maximum of 3 times, each for $15 \mathrm{~s} .{ }^{83}$ The diameter of the suction catheter in both groups was half the inner diameter of the ETT; the suction catheter was inserted no further than the end of the ETT in the shallow suction group. ${ }^{83}$ In the deep suction group, the catheter was passed through the ETT until resistance was met, then pulled back $1 \mathrm{~cm}$ before suctioning was performed. ${ }^{83}$ They noted that breathing frequency and $\mathrm{S}_{\mathrm{pO}_{2}}$ changes were similar between the groups. ${ }^{83}$ The subjects in the deep suction group required suctioning less frequently. ${ }^{83}$ Irajpour et $\mathrm{al}^{84}$ reported the effects of shallow and deep suctioning techniques on heart rate, systolic blood pressure, diastolic blood pressure, and mean arterial pressure. The changes were similar; however, the investigators did report a slight increase in heart rate and blood pressure measures with deep suctioning. ${ }^{84}$ They noted that increases in each, even to a small degree, could have adverse effects on some patients and that monitoring is necessary during suctioning, particularly during deep suctioning. ${ }^{84}$

In a parallel randomized controlled trial, Shamali et al ${ }^{85}$ compared what they called routine ETT suctioning with a minimally invasive ETT suctioning technique. The routine ETT suctioning technique consisted of manual hyperinflation and preoxygenation for $1 \mathrm{~min}$, and instillation of $8 \mathrm{~mL}$ of sterile saline solution. ${ }^{85}$ The suction catheter was advanced down the ETT until resistance was met and withdrawn $1 \mathrm{~cm}$; suctioning was then performed by using a vacuum pressure of -100 to $-200 \mathrm{~mm} \mathrm{Hg}$ for a maximum of $10 \mathrm{~s}^{85}$ The minimally invasive ETT suctioning technique consisted of preoxygenation by the mechanical ventilator for $1 \mathrm{~min}$. The suction catheter was advanced to the distal end of the ETT; suctioning was then performed by using a vacuum pressure of -80 to $-120 \mathrm{~mm} \mathrm{Hg}$ for a maximum of $10 \mathrm{~s} .{ }^{85}$ The study investigators noted that the minimally invasive ETT suctioning group had statistically fewer alterations in systolic blood pressure, diastolic blood pressure, mean arterial pressure, and $\mathrm{S}_{\mathrm{pO}_{2}}$ but not in heart rate. ${ }^{85}$ Although it seems that a less-invasive method of suctioning may be warranted to reduce alterations in some physiologic measures due to less physical stimulation, it is unclear which component(s) of routine ETT suctioning (normal saline solution, manual hyperinflation, deep suctioning) impacted these results. In an experimental within-subject designed study that evaluated shallow and deep suctioning techniques on infants at high risk, Ahn and Hwang ${ }^{86}$ noted that deep suctioning did not guarantee the removal of lower airway secretions in neonatal subjects. In fact, they reported that it caused more-direct airway trauma, as evidenced by epithelial damage noted in respiratory aspirates. ${ }^{86}$

Based on the available evidence, it seems that both shallow and deep suctioning techniques cause similar alterations in physiologic indices. Although deep suctioning may result in less-frequent suctioning events, it may be associated with airway trauma. The 2010 AARC $\mathrm{CPG}^{1}$ recommended the shallow suction technique, citing no definitive benefit of deep suctioning. Since that guideline, no new evidence convincingly impacts this recommendation. It seems that the shallow suctioning technique should be used routinely to avoid potential airway trauma (evidence level B, median appropriateness score 7.7, range 7 - 8). Deep suctioning should generally be used only when shallow suctioning is ineffective with consideration of the potential for airway trauma and the negative impact on physiologic indices (evidence level B, median appropriateness score 7.2 , range 7-8).

\section{Bronchoscopy Versus Artificial Airway Suctioning}

Bronchoscopy has historically been used for diagnostic purposes or to obtain secretions from specific areas of the lung but not for routine use to clear secretions. A review of the literature yielded 1 study related to routine bronchoscopy use. ${ }^{87}$ Qiao et al ${ }^{87}$ conducted a trial in which 73 adult subjects with a COPD exacerbation were randomized to either routine artificial airway suctioning by using bronchoscopy in conjunction with conventional artificial airway suctioning or conventional artificial airway suctioning alone. The investigators found that there were significantly better outcomes in terms of appearance of the pulmonary infection control window, days of invasive mechanical ventilation, total days of mechanical ventilation, hospital LOS, weaning success, incidence of VAP, and mortality with routine bronchoscopy use in conjunction with conventional artificial airway suctioning. The 2010 AARC CPG ${ }^{1}$ did not address bronchoscopy use for routine secretion removal because only 1 study $^{87}$ relevant to this topic has been published to date and that study had limited scope, this committee felt that the routine use of bronchoscopy for secretion removal cannot be recommended (evidence level $\mathrm{C}$, all the committee members rated the appropriateness score at 9).

\section{Artificial Airway (Tube) Scraping Devices}

Various devices have been developed for the purpose of clearing ETTs of secretions and biofilm that might increase $R_{a w}$ and peak inspiratory pressure, and ultimately result in complete airway obstruction. These devices are used in addition to standard suction catheters to maintain the inner diameter of ETTs. A review of 


\section{AarC Clinical Practice Guidelines: Artificial Airway Suctioning}

Table 1. Summary of Recommendations for Each PICO Question

PICO Question

ing in the neonatal, pediatric,and adult population?

Should artificial airway suctioning be performed on a schedule or only on an as-needed basis?

Should artificial airway suctioning be performed by using open or closed systems?

Should patients receive preoxygenation and/or hyperoxygenation before suctioning every time?

Should normal saline solution lavage be used during suctioning of the artificial airway?

Should open suctioning of an artificial airway be performed as a clean procedure or as a sterile procedure?

What size suction catheter and what vacuum pressure should clinicians use to suction artificial airways?

What limit should be imposed on the duration of the suctioning event?

Is a shallow suctioning technique preferred over a deep suctioning technique?
Summary of Recommendations

Breath sounds, visual secretions in the artificial airway, and a sawtooth pattern on the mechanical ventilation waveform provide the best indications for endotracheal suctioning in the adult and pediatric population (evidence level B, all the committee members rated the appropriateness score at 8 )

An acute increase in airway resistance may be an indicator for the need for artificial airway suctioning in neonates (evidence level B, median appropriateness score 7, range 7-8)

Mitigation strategies such as adequate sedation, preoxygenation, and suctioning only if indicated may reduce the incidence and severity of potential complications, including but not limited to increased heart rate, mean arterial pressure, ICP, cardiac arrythmias, and oxygen desaturation (evidence level B, median appropriateness score 7.6, range 7-9)

As-needed suctioning is just as effective as routine suctioning and does not increase morbidity or mortality in neonatal and pediatric populations (evidence level $\mathrm{B}$, all the committee members rated the appropriateness score at 8 )

Either the closed suction system or the open suction system can be used safely and effectively to remove secretions from the adult patient with an artificial airway (evidence level B, median appropriateness score 8.3, range 7-9)

Adult and pediatric patients should be preoxygenated before artificial airway suctioning (evidence level B, all the committee members rated the appropriateness score at 9)

The routine use of normal saline solution (generally should be avoided) is unnecessary during artificial airway suctioning (evidence level $\mathrm{B}$, median appropriateness score 8.85, range 8-9)

The clinician should use a sterile procedure for open suctioning events to protect the patient from potential cross-contamination (evidence level $\mathrm{C}$, all the committee members rated the appropriateness score at 7)

Suction catheters should occlude $<70 \%$ of the ETT lumen in infants, children, and adults (evidence level $\mathrm{C}$, all the committee members rated the appropriateness score at 7)

Suction pressures should be kept below $-200 \mathrm{~mm} \mathrm{Hg}$ in adults and below $-120 \mathrm{~mm} \mathrm{Hg}$ in the neonatal and pediatric population (evidence level $\mathrm{C}$, all the committee members rated the appropriateness score at 7 )

Efforts to set the suction pressure as low as possible and effectively clear secretions should be made (evidence level C, all the committee members rated the appropriateness score at 9)

The clinician should keep the suctioning procedure as brief as possible and no longer than $15 \mathrm{~s}$ (evidence level $\mathrm{C}$, all the committee members rated the appropriateness score at 9)

A shallow suctioning technique should be used routinely (evidence level B, median appropriateness score 7.7, range 7-8).

Deep suctioning should generally be used only when shallow suctioning is ineffective with consideration of the potential for airway trauma and the negative impact on physiologic indices (evidence level B, median appropriateness score 7.2, range 7-8).

(Continued) 
AarC Clinical Practice Guidelines: Artificial Airway Suctioning

Table 1. Continued

\begin{tabular}{|c|c|}
\hline PICO Question & Summary of Recommendations \\
\hline $\begin{array}{l}\text { When should bronchoscopy be used in lieu of open or closed suctioning } \\
\text { techniques? }\end{array}$ & $\begin{array}{l}\text { Routine use of bronchoscopy for secretion removal is not recom- } \\
\text { mended (evidence level C, all the committee members rated the } \\
\text { appropriateness score at 9) }\end{array}$ \\
\hline $\begin{array}{l}\text { When should tube scraping devices be used in addition to suction } \\
\text { catheters? }\end{array}$ & $\begin{array}{l}\text { There is evidence that supports the use of devices use to clear ETTs } \\
\text { when an increase in } \mathrm{R}_{\mathrm{aw}} \text { are suspected due to secretion accumula- } \\
\text { tion (evidence level B, median appropriateness score 8.5, range 8- } \\
\text { 9). }\end{array}$ \\
\hline $\begin{array}{l}\text { PICO = patient, intervention, comparison, outcome) } \\
\text { ICP }=\text { intracranial pressure } \\
\text { ETT = endotracheal tube } \\
\mathrm{R}_{\mathrm{aw}}=\text { airway resistance }\end{array}$ & \\
\hline
\end{tabular}

the literature resulted in 4 studies $^{88-91}$ that assessed changes in $\mathrm{R}_{\mathrm{aw}}$ when these devices were used in adult subjects. In separate studies of subjects who required mechanical ventilation, Conti et $\mathrm{al}^{88}$ and Scott et $\mathrm{al}{ }^{89}$ noted significant reductions in $\mathrm{R}_{\mathrm{aw}}$ after the use of experimental obstruction removal devices. In a laboratory study, Adi et $\mathrm{al}^{90}$ found that a device designed to clear ETTs of secretions was able to restore inspiratory $R_{a w}$ of ETTs removed from subjects to levels comparable with that of unused ETTs. In another ex vivo study, by Waters et al, ${ }^{91}$ an ETT cleaning device was effective at reducing luminal biofilm secretions and improving pressure drop (an indicator of $\mathrm{R}_{\mathrm{aw}}$ ) in size $7.5 \mathrm{~mm}$ and $8.0 \mathrm{~mm}$ ETTs. Of note, the device was not effective at clearing secretions to the level of unused ETTs. Two randomized controlled trials ${ }^{92,93}$ found these devices to be effective at reducing mucus accumulation, overall ETT occlusion, maximal ETT occlusion, and biofilm thickness when compared with standard blind suctioning alone. However, these studies did not show improvement in outcomes such as mechanical ventilation days, days in ICU, or days of intubation. ${ }^{92,93}$ Evidence supports the use of devices used to clear ETTs when an increase in $\mathrm{R}_{\mathrm{aw}}$ and peak inspiratory pressure due to secretion accumulation is suspected (evidence level B, median appropriateness score 8.5, range 8-9). It is not known if these devices should be used intermittently or as part of routine airway management.

\section{Summary}

The results of this systematic review are summarized in Table 1. Although several references were included in this systematic review, the quality of the evidence was low. This was also true for all PICO questions, which necessitated that all recommendations be made based on low-level evidence and/or expert opinion. It is imperative to emphasize that, whereas recommendations made in this CPG were based on an exhaustive review of the literature, anecdotal evidence and the clinical experience of the committee members also played a role in the final recommendations. The numerous variables associated with artificial airway suctioning (type of artificial airway, heterogeneous patient population, clinical setting, and available resources), inconsistent experimental designs of the studies reviewed, and overall low quality of the available evidence to date make it difficult to isolate a definitive set of recommendations at this time based exclusively on the literature. The recommendations made by the committee members are intended to support clinicians in their efforts to provide a safe and effective artificial airway suctioning practice. Many of the recommendations informed by this literature review were in agreement with recommendations from the 2010 AARC CPG. ${ }^{1}$

The major limitation of this CPG is the overall lack of high-quality evidence to drive clinical recommendations. That said, it should be noted that other review articles agree with our recommendations on the timing and frequency of artificial airway suctioning, use of closed suction systems, preoxygenation before suctioning, avoidance of normal saline solution instillation during the suctioning procedure, use of the sterile procedure for open suction events, suction catheter size and vacuum pressure settings, duration of suction procedure, ${ }^{2}$ use of a shallow suctioning technique, and the use of tube scraping devices to remove accumulated biofilm and secretions in the artificial airway to reduce $R_{a w}$ and peak inspiratory pressure. ${ }^{82,94-104} \mathrm{~A}$ review by Dodek et al ${ }^{105}$ reached the same conclusion as we did on the use of closed suction systems over open suction systems but did so based solely on economic reasons. Day et $\mathrm{al}^{98}$ recommended a deep suctioning technique, despite citing the evidence of greater alterations in vital signs with this method.

Artificial airway suctioning remains an integral component of proper artificial airway management. The suctioning procedure is associated with well-known risks and complications that must be weighed against the potential benefit for the patient. Although this systematic review yielded more evidence than the 2010 AARC $\mathrm{CPG}^{1}$ on 


\section{AARC Clinical Practice Guidelines: Artificial Airway Suctioning}

artificial airway suctioning to support recommendations, the strength of the evidence remains weak and did not warrant major changes to the previous recommendations. More robust, well-designed research studies are needed in this area of respiratory care to provide caregivers with information to assist in safe, appropriate suctioning of the artificial airway.

\section{REFERENCES}

1. American Association for Respiratory Care. AARC Clinical Practice Guidelines. Endotracheal suctioning of mechanically ventilated patients with artificial airways 2010. Respir Care 2010;55(6):758764.

2. Maggiore SM, Lellouche F, Pignataro C, Girou E, Maitre B, Richard JC, et al. Decreasing the adverse effects of endotracheal suctioning during mechanical ventilation by changing practice. Respir Care 2013;58(10):1588-1597.

3. Dexter AM, Scott JB. Airway management and ventilator-associated events. Respir Care 2019;64(8):986-993.

4. Seymour CW, Cross BJ, Cooke CR, Gallop RL, Fuchs BD. Physiologic impact of closed-system endotracheal suctioning in spontaneously breathing patients receiving mechanical ventilation. Respir Care 2009;54(3):367-374.

5. Carroll P. Enhancing the safety of medical suction through innovative technology. Can J Respir Ther 2010;46(2):47-49.

6. Fitch K, Bernstein SJ, Aguilar MD, Burnand B, LaCalle JR, Lazaro $\mathrm{P}$, et al. The RAND/UCLA appropriateness method user's manual. Santa Monica: RAND; 2001.

7. Prendiville A, Thomson A, Silverman M. Effect of tracheobronchial suction on respiratory resistance in intubated preterm babies. Arch Dis Child 1986;61(12):1178-1183.

8. Seyedhejazi M, Sheikhzade D, Aliakbari Sharabiani B, Abri R, Sadeghian M. Evaluating the effects of post-intubation endotracheal suctioning before surgery on respiratory parameters in children with airway secretion. Anesth Pain Med 2019;9(3)e86486.

9. Guglielminotti J, Alzieu M, Maury E, Guidet B, Offenstadt G. Bedside detection of retained tracheobronchial secretions in patients receiving mechanical ventilation: is it time for tracheal suctioning? Chest 2000;118(4): 1095-1099.

10. Sole ML, Bennett M, Ashworth S. Clinical indicators for endotracheal suctioning in adult patients receiving mechanical ventilation. Am J Crit Care 2015;24(4):318-324; quiz 325.

11. Lucchini A, Zanella A, Bellani G, Gariboldi R, Foti G, Pesenti A, Fumagalli R. Tracheal secretion management in the mechanically ventilated patient: comparison of standard assessment and an acoustic secretion detector. Respir Care 2011;56(5):569-603.

12. Beuret P, Philippon B, Fabre X, Kaaki M. Effect of tracheal suctioning on aspiration past the tracheal tube cuff in mechanically ventilated patients. Ann Intensive Care 2012;2(1):45.

13. Durand M, Sangha B, Cabal LA, Hoppenbrouwers T, Hodgman JE. Cardiopulmonary and intracranial pressure changes related to endotracheal suctioning in preterm infants. Crit Care Med 1989;17 (6):506-510.

14. Fanconi S, Duc G. Intratracheal suctioning in sick preterm infants: prevention of intracranial hypertension and cerebral hypoperfusion by muscle paralysis. Pediatrics 1987;79(4):538-543.

15. Simbruner G, Coradello H, Fodor M, Havelec L, Lubec G, Pollak A. Effect of tracheal suction on oxygenation, circulation, and lung mechanics in newborn infants. Arch Dis Child 1981;56(5):326-330.

16. Kaiser JR, Gauss CH, Williams DK. Tracheal suctioning is associated with prolonged disturbances of cerebral hemodynamics in very low birth weight infants. J Perinatol 2008;28(1):34-41.
17. Tingay DG, Copnell B, Mills JF, Morley CJ, Dargaville PA. Effects of open endotracheal suction on lung volume in infants receiving HFOV. Intensive Care Med 2007;33(4):689-693.

18. Morrow B, Futter M, Argent A. Effect of endotracheal suction on lung dynamics in mechanically-ventilated paediatric patients. Aust $\mathrm{J}$ Physiother 2006;52(2):121-126.

19. Scoble MK, Copnell B, Taylor A, Kinney S, Shann F. Effect of reusing suction catheters on the occurrence of pneumonia in children. Heart Lung 2001;30(3):225-233.

20. Boothroyd AE, Murthy BV, Darbyshire A, Petros AJ. Endotracheal suctioning causes right upper lobe collapse in intubated children. Acta Paediatr 1996;85(12):1422-1425.

21. Fisher DM, Frewen T, Swedlow DB. Increase in intracranial pressure during suctioning - stimulation vs. rise in $\mathrm{PaCO}_{2}$. Anesthesiology 1982;57(5):416-417.

22. Jongerden IP, Kesecioglu J, Speelberg B, Buiting AG, Leversteinvan Hall MA, Bonten MJ. Changes in heart rate, mean arterial pressure, and oxygen saturation after open and closed endotracheal suctioning: a prospective observational study. J Crit Care 2012;27 (6):647-654

23. Kerr ME, Weber BB, Sereika SM, Darby J, Marion DW, Orndoff PA. Effect of endotracheal suctioning on cerebral oxygenation in traumatic brain-injured patients. Crit Care Med 1999;27(12):27762781.

24. Gemma M, Tommasino C, Cerri M, Giannotti A, Piazzi B, Borghi T. Intracranial effects of endotracheal suctioning in the acute phase of head injury. J Neurosurg Anesthesiol 2002;14(1):50-54.

25. Brucia J, Rudy E. The effect of suction catheter insertion and tracheal stimulation in adults with severe brain injury. Heart Lung 1996;25 (4):295-303.

26. Clark AP, Winslow EH, Tyler DO, White KM. Effects of endotracheal suctioning on mixed venous oxygen saturation and heart rate in critically ill adults. Heart Lung 1990;19(5 Pt 2):552-557.

27. Bourgault AM, Brown CA, Hains SM, Parlow JL. Effects of endotracheal tube suctioning on arterial oxygen tension and heart rate variability. Biol Res Nurs 2006;7(4):268-278.

28. Guglielminotti J, Desmonts JM, Dureuil B. Effects of tracheal suctioning on respiratory resistances in mechanically ventilated patients. Chest 1998;113(5):1335-1338.

29. Van de Leur JP, Zwaveling JH, Loef BG, Van der Schans CP. Patient recollection of airway suctioning in the ICU: routine versus a minimally invasive procedure. Intensive Care Med 2003;29(3):433-436.

30. Van de Leur JP, Zwaveling JH, Loef BG, Van der Schans CP. Endotracheal suctioning versus minimally invasive airway suctioning in intubated patients: a prospective randomised controlled trial. Intensive Care Med 2003;29(3):426-432.

31. Walsh JM, Vanderwarf C, Hoscheit D, Fahey PJ. Unsuspected hemodynamic alterations during endotracheal suctioning. Chest 1989;95 (1):162-165.

32. Cordero L, Sananes M, Ayers LW. A comparison of two airway suctioning frequencies in mechanically ventilated, very-low-birthweight infants. Respir Care 2001;46(8):783-788.

33. Lema-Zuluaga GL, Fernandez-Laverde M, Correa-Varela AM, Zuleta-Tobón JJ. As-needed endotracheal suctioning protocol vs a routine endotracheal suctioning in pediatric intensive care unit: a randomized controlled trial. Colombia Medica (Cali) 2018;49 (2):148-153

34. Witmer MT, Hess D, Simmons M. An evaluation of the effectiveness of secretion removal with the Ballard closed-circuit suction catheter. Respir Care 1991;36(8):844-848.

35. Lasocki S, Lu Q, Sartorius A, Fouillat D, Remerand F, Rouby J-J. Open and closed-circuit endotracheal suctioning in acute lung injury: efficiency and effects on gas exchange. Anesthesiology 2006;104 (1):39-47. 


\section{AARC Clinical Practice Guidelines: Artificial Airway Suctioning}

36. Afshari A, Safari M, Oshvandi K, Soltanian AR. The effect of the open and closed system suctions on cardiopulmonary parameters: time and costs in patients under mechanical ventilation. Nurs Midwifery Stud 2014;3(2):e14097.

37. Åkerman E, Larsson C, Ersson A. Clinical experience and incidence of ventilator-associated pneumonia using closed versus open suctionsystem. Nurs Crit Care 2014;19(1):34-41.

38. Dastdadeh R, Ebadi A, Vahedian-Azimi A. Comparison of the effect of open and closed endotracheal suctioning methods on pain and agitation in medical ICU patients: a clinical trial. Anesth Pain Med 2016;6(5):e38337.

39. Fernandez MD, Piacentini E, Blanch L, Fernandez R. Changes in lung volume with three systems of endotracheal suctioning with and without pre-oxygenation in patients with mild-to-moderate lung failure. Intensive Care Med 2004;30(12):2210-2215.

40. Lee CK, Ng KS, Tan SG, Ang R. Effect of different endotracheal suctioning systems on cardiorespiratory parameters of ventilated patients. Ann Acad Med Singapore 2001;30(3):239-244.

41. Ozden D, Gorgulu RS. Effects of open and closed suction systems on the haemodynamic parameters in cardiac surgery patients. Nurs Crit Care 2015;20(3):118-125.

42. Topeli A, Harmanci A, Cetinkaya Y, Akdeniz S, Unal S. Comparison of the effect of closed versus open endotracheal suction systems on the development of ventilator-associated pneumonia. J Hosp Infect 2004;58(1):14-19.

43. Johnson KL, Kearney PA, Johnson SB, Niblett JB, MacMillan NL, McClain RE. Closed versus open endotracheal suctioning: costs and physiologic consequences. Crit Care Med 1994;22(4):658-666.

44. Uğraş GA, Aksoy G. The effects of open and closed endotracheal suctioning on intracranial pressure and cerebral perfusion pressure: a crossover, single-blind clinical trial. J Neurosci Nurs 2012;44(6):E1-8.

45. Cardoso JM, Kusahara DM, Guinsburg R, Pedreira ML. Randomized crossover trial of endotracheal tube suctioning systems use in newborns. Nurs Crit Care 2017;22(5):276-283.

46. Chegondi M, Francis T, Lin W-C, Naqvi S, Raszynski A, Totapally BR. Effects of closed endotracheal suctioning on systemic and cerebral oxygenation and hemodynamics in children. Pediatr Crit Care Med 2018;19(1):e23-e30.

47. Choong K, Chatrkaw P, Frndova H, Cox PN. Comparison of loss in lung volume with open versus in-line catheter endotracheal suctioning. Pediatr Crit Care Med 2003;4(1):69-73.

48. Evans J, Syddall S, Butt W, Kinney S. Comparison of open and closed suction on safety, efficacy and nursing time in a paediatric intensive care unit. Aust Crit Care 2014;27(2):70-74.

49. Kalyn A, Blatz S, Feuerstake S, Paes B, Bautista C. Closed suctioning of intubated neonates maintains better physiologic stability: a randomized trial. J Perinatol 2003;23(3):218-222.

50. Morrow BM, Mowzer R, Pitcher R, Argent AC. Investigation into the effect of closed-system suctioning on the frequency of pediatric ventilator-associated pneumonia in a developing country. Pediatr Crit Care Med 2012;13(1):e25-e32.

51. de Paula LCS, Ceccon MEJ. Randomized, comparative analysis between two tracheal suction systems in neonates. Rev Assoc Med Bras (1992) 2010;56(4):434-439.

52. Pirr SM, Lange M, Hartmann C, Bohnhorst B, Peter C. Closed versus open endotracheal suctioning in extremely low-birth-weight neonates: a randomized, crossover trial. Neonatology 2013;103(2):124130 .

53. Cordero L, Sananes M, Ayers LW. Comparison of a closed (Trach Care MAC) with an open endotracheal suction system in small premature infants. J Perinatol 2000;20(3):151-156.
54. Adams DH, Hughes M, Elliott TS. Microbial colonization of closedsystem suction catheters used in liver transplant patients. Intensive Crit Care Nurs 1997;13(2):72-76.

55. David D, Samuel P, David T, Keshava SN, Irodi A, Peter JV. An open-labelled randomized controlled trial comparing costs and clinical outcomes of open endotracheal suctioning with closed endotracheal suctioning in mechanically ventilated medical intensive care patients. J Crit Care 2011;26(5):482-488.

56. Deppe SA, Kelly JW, Thoi LL, Chudy JH, Longfield RN, Ducey JP, et al. Incidence of colonization, nosocomial pneumonia, and mortality in critically ill patients using a Trach Care closed-suction system versus an open-suction system: prospective, randomized study. Crit Care Med 1990;18(12):1389-1393.

57. Hamishekar H, Shadvar K, Taghizadeh M, Golzari SE, Mojtahedzadeh M, Soleimanpour H, Mahmoodpoor A. Ventilatorassociated pneumonia in patients admitted to intensive care units, using open or closed endotracheal suctioning. Anesth Pain Med 2014;4(5):e21649.

58. Jongerden IP, Buiting AG, Leverstein-van Hall MA, Speelberg B, Zeidler S, Kesecioglu J, Bonten MJ. Effect of open and closed endotracheal suctioning on cross-transmission with Gram-negative bacteria: a prospective crossover study. Crit Care Med 2011;39(6):13131321.

59. Zeitoun SS, de Barros ALBL, Diccini S. A prospective, randomized study of ventilator-associated pneumonia in patients using a closed vs. open suction system. J Clin Nurs 2003;12(4):484-489.

60. Kerem E, Yatsiv I, Goitein KJ. Effect of endotracheal suctioning on arterial blood gases in children. Intensive Care Med 1990;16(2):9599.

61. Lookinland S, Appel PL. Hemodynamic and oxygen transport changes following endotracheal suctioning in trauma patients. Nurs Res 1991;40(3):133-139.

62. Preusser BA, Stone KS, Gonyon DS, Winningham ML, Groch KF, Karl JE. Effects of two methods of preoxygenation on mean arterial pressure, cardiac output, peak airway pressure, and postsuctioning hypoxemia. Heart Lung 1988;17(3):290-299.

63. de Freitas Vianna JR, Pires Di Lorenzo VA, da Silva Simões MML, Jamami M. Comparing the effects of two different levels of hyperoxygenation on gas exchange during open endotracheal suctioning: a randomized crossover study. Respir Care 2017;62(1):92-101.

64. Demir F, Dramali A. Requirement for 100\% oxygen before and after closed suction. J Adv Nurs 2005;51(3):245-251.

65. Ackerman MH. The effect of saline lavage prior to suctioning. Am J Crit Care 1993;2(4):326-330.

66. Ackerman MH, Mick DJ. Instillation of normal saline before suctioning in patients with pulmonary infections: a prospective randomized controlled trial. Am J Crit Care 1998;7(4):261-266.

67. Akgul S, Akyolcu N. Effects of normal saline on endotracheal suctioning. J Clin Nurs 2002;11(6):826-830.

68. Gray JE, MacIntyre NR, Kronenberger WG. The effects of bolus normal-saline instillation in conjunction with endotracheal suctioning. Respir Care 1990;35(8):785-790.

69. Ji YR, Kim HS, Park JH. Instillation of normal saline before suctioning in patients with pneumonia. Yonsei Med J 2002;43(5):607-612.

70. Kinloch D. Instillation of normal saline during endotracheal suctioning: effects on mixed venous oxygen saturation. Am J Crit Care 1999;8(4):231-240; quiz 241-242.

71. Owen EB, Woods CR, O'Flynn JA, Boone MC, Calhoun AW, Montgomery VL. A bedside decision tree for use of saline with endotracheal tube suctioning in children. Crit Care Nurse 2016;36(1):e1e10.

72. Ridling DA, Martin LD, Bratton SL. Endotracheal suctioning with or without instillation of isotonic sodium chloride solution in critically ill children. Am J Crit Care 2003;12(3):212-219. 


\section{AarC Clinical Practice Guidelines: Artificial Airway Suctioning}

73. O’Neal PV, Grap MJ, Thompson C, Dudley W. Level of dyspnoea experienced in mechanically ventilated adults with and without saline instillation prior to endotracheal suctioning. Intensive Crit Care Nurs 2001;17(6):356-363.

74. McKinley DF, Kinney SB, Copnell B, Shann F. Long-term effects of saline instilled during endotracheal suction in pediatric intensive care: a randomized trial. Am J Crit Care 2018;27(6):486-494.

75. Caruso P, Denari S, Ruiz SAL, Demarzo SE, Deheinzelin D. Saline instillation before tracheal suctioning decreases the incidence of ventilator-associated pneumonia. Crit Care Med 2009;37(1):32-38.

76. Morrow BM, Argent AC. A comprehensive review of pediatric endotracheal suctioning: effects, indications, and clinical practice. Pediatr Crit Care Med 2008;9(5):465-477.

77. Tablan OC, Anderson LJ, Besser R, Bridges C, Hajjeh R; CDC; Healthcare Infection Control Practices Advisory Committee. Guidelines for preventing health-care-associated pneumonia, 2003: recommendations of $\mathrm{CDC}$ and the Healthcare Infection Control Practices Advisory Committee. MMWR Recomm Rep 2004;53(RR3):1-36.

78. Javadi M, Hejr H, Zolad M, Khalili A, Paymard A. Comparing the effect of endotracheal tube suction using open method with two different size catheters 12 and 14 on discharge secretion, pain, heart rate, blood pressure, and arterial oxygen saturation of patients in the intensive care unit: a randomized clinical trial. Ann Trop Med Public Health 2017;10(5):1312-1317.

79. Yousefi H, Vahdatnejad J, Yazdannik AR. Comparison of the effects of two levels of negative pressure in open endotracheal tube suction on the physiological indices among patients in intensive care units. Iran J Nurs Midwifery Res 2014;19(5):473-477.

80. Singh NC, Kissoon N, Frewen T, Tiffin N. Physiological responses to endotracheal and oral suctioning in paediatric patients: the influence of endotracheal tube sizes and suction pressures. Clin Intensive Care 1991;2(6):345-350.

81. Pedersen CM, Rosendahl-Nielsen M, Hjermind J, Egerod I. Endotracheal suctioning of the adult intubated patient - what is the evidence? Intensive Crit Care Nurs 2009;25(1):21-30.

82. Davies JD, Hess DR. Airway management. In Hess DR, MacIntyre NR, Mishoe SC, Galvin WF, Respiratory care principles and practice. 4th edition. Burlington, MA: Jones \& Bartlett; 2021:391-442.

83. Abbasinia M, Irajpour A, Babaii A, Shamali M, Vahdatnezhad J. Comparison the effects of shallow and deep endotracheal tube suctioning on respiratory rate, arterial blood oxygen saturation and number of suctioning in patients hospitalized in the intensive care unit: a randomized controlled trial. J Caring Sci 2014;3(3):157-164.

84. Irajpour A, Abbasinia M, Hoseini A, Kashefi P. Effects of shallow and deep endotracheal tube suctioning on cardiovascular indices in patients in intensive care units. Iran J Nurs Midwifery Res 2014;19 (4):366-370.

85. Shamali M, Abbasinia M, Østergaard B, Konradsen H. Effect of minimally invasive endotracheal tube suctioning on physiological indices in adult intubated patients: an open-labelled randomised controlled trial. Aust Crit Care 2019;32(3):199-204.

86. Ahn Y, Hwang T. The effects of shallow versus deep endotracheal suctioning on the cytological components of respiratory aspirates in high-risk infants. Respiration 2003;70(2):172-178.

87. Qiao Z, Yu J, Yu K, Zhang M. The benefit of daily sputum suction via bronchoscopy in patients of chronic obstructive pulmonary disease with ventilators: a randomized controlled trial. Medicine (Baltimore) 2018;97(31):e11631.
88. Conti G, Rocco M, De Blasi RA, Lappa A, Antonelli M, Bufi M, Gasparetto A. A new device to remove obstruction from endotracheal tubes during mechanical ventilation in critically ill patients. Intensive Care Med 1994;20(8):573-576.

89. Scott JB, Dubosky MN, Vines DL, Sulaiman AS, Jendral KR, Singh $\mathrm{G}$, et al. Evaluation of endotracheal tube scraping on airway resistance. Respir Care 2017;62(11):1423-1427.

90. Adi NA, Tomer NT, Bergman GB, Kishinevsky EK, Wyncoll DW. Effects of prolonged mechanical ventilation with a closed suction system on endotracheal tube resistance and its reversibility by a closed suction cleaning system. Anaesth Intensive Care 2013;41 (6):728-735

91. Waters C, Wiener RC, Motlagh HM. Ex vivo evaluation of secretionclearing device in reducing airway resistance within endotracheal tubes. Crit Care Res Pract 2018;2018:3258396.

92. Pinciroli R, Mietto C, Piriyapatsom A, Chenelle CT, Thomas JG, Pirrone M, et al. Endotracheal tubes cleaned with a novel mechanism for secretion removal: a randomized controlled clinical study. Respir Care 2016;61(11):1431-1439.

93. Berra L, Coppadoro A, Bittner EA, Kolobow T, Laquerriere P, Pohlmann JR, et al. A clinical assessment of the mucus shaver: a device to keep the endotracheal tube free from secretions. Crit Care Med 2012;40(1):119-124.

94. Branson RD, Gomaa D, Rodriquez D, Jr. Management of the artificial airway. Respir Care 2014;59(6):974-989; discussion 989-990.

95. Ireton J. Tracheostomy suction: a protocol for practice. Paediatr Nurs 2007;19(10):14-18.

96. Jongerden IP, Rovers MM, Grypdonck MH, Bonten MJ. Open and closed endotracheal suction systems in mechanically ventilated intensive care patients: a meta-analysis. Crit Care Med 2007;35(1):260270.

97. Oh H, Seo W. A meta-analysis of the effects of various interventions in preventing endotracheal suction-induced hypoxemia. J Clin Nurs 2003;12(6):912-924.

98. Day T, Farnell S, Wilson-Barnett J. Suctioning: a review of current research recommendations. Intensive Crit Care Nurs 2002;18 (2):79-89.

99. Stone KS. Ventilator versus manual resuscitation bag as the method for delivering hyperoxygenation before endotracheal suctioning. AACN Clin Issues Crit Care Nurs 1990;1(2):289-299.

100. Lorente L, Blot S, Rello J. New issues and controversies in the prevention of ventilator-associated pneumonia. Am J Respir Crit Care Med 2010;182(7):870-876

101. Kerr ME, Rudy EB, Brucia J, Stone KS. Head-injured adults: recommendations for endotracheal suctioning. J Neurosci Nurs 1993;25 (2):86-91.

102. Liao Y, Zeng Q, Xu Y, Yang Q, Ye J, Yin X. Deep suction perform more effective than shallow suction in trachea intubation patients: a meta-analysis of randomized control trials. Acta Medica Mediterranea 2019;35:421-428.

103. Gillies D, Spence K. Deep versus shallow suction of endotracheal tubes in ventilated neonates and young infants. Cochrane Database Syst Rev 2011(7):CD003309.

104. Mietto C, Foley K, Salerno L, Oleksak J, Pinciroli R, Goverman J, Berra L. Removal of endotracheal tube obstruction with a secretion clearance device. Respir Care 2014;59(9):e122-e126.

105. Dodek P, Keenan S, Cook D, Heyland D, Jacka M, Hand L, et al; Canadian Critical Care Society. Evidence-based clinical practice guideline for the prevention of ventilator-associated pneumonia. Ann Intern Med 2004;141(4):305-313. 